\title{
Endothelial dysfunction in streptozotocin-diabetic rats is not reversed by dietary probucol or simvastatin supplementation
}

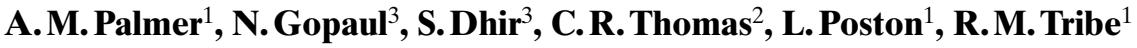 \\ ${ }^{1}$ Division of Obstetrics and Gynaecology, United Medical and Dental Schools, St Thomas' Hospital, London, UK \\ ${ }^{2}$ Division of Medicine, United Medical and Dental Schools, St Thomas' Hospital, London, UK \\ ${ }^{3}$ The William Harvey Research Institute, London, UK
}

\begin{abstract}
Summary Oxidative stress and dyslipidaemia are key features of diabetes mellitus and may be involved in mediating the vascular endothelial dysfunction associated with this disease. The aim of this study was to examine the effect of dietary lipid-lowering and antioxidant agents on vascular endothelial function and oxidative stress. Diabetic male Sprague-Dawley rats (i. v. streptozotocin, $45 \mathrm{mg} / \mathrm{kg}$ ) were fed for 4 weeks on a standard diet or on a diet supplemented with either the lipid-lowering antioxidant probucol (1\% $\mathrm{w} / \mathrm{w}$ in diet) or the 3-hydroxy 3-methylglutaryl coenzyme-A (HMG-CoA) reductase inhibitor simvastatin $(0.01 \% \mathrm{w} / \mathrm{w}$ in diet $)$. Responses to noradrenaline, acetylcholine, and sodium nitroprusside were assessed in small mesenteric arteries (mean internal diameter $300 \pm 5 \mu \mathrm{m}, n=80$ ) mounted on a small vessel myograph. Plasma concentrations of total cholesterol and triglycerides were significantly raised in standard-fed diabetic rats and significantly reduced in probucol and simvastatin-fed diabetic rats. 8-epi-
\end{abstract}

prostaglandin $(\mathrm{PG}) \mathrm{F}_{2 \alpha}$, an indicator of oxidative stress, was raised in liver and aorta from diabetic rats compared to controls. Probucol supplementation reduced 8-epi-PGF $\mathrm{PG}_{2} \alpha$ in aorta and liver of diabetic rats but increased 8 -epi- $\mathrm{PGF}_{2} \alpha$ content in plasma and aorta from control animals. The abnormal relaxation to acetylcholine in arteries from the diabetic rats $\left(\mathrm{pEC}_{50}\right.$ diabetic $6.763 \pm 0.172$ vs control $7.541 \pm 0.175 ; p<0.05$ ) was not improved by probucol or simvastatin. These data, therefore, do not support a role for oxidative stress or dyslipidaemia in mediating the impaired ACh-induced endothelium-dependent relaxation of small mesenteric arteries from the streptozotocin-diabetic rat. [Diabetologia (1998) 41: 157-164]

Keywords Diabetes mellitus, vascular endothelium, lipids, antioxidants, resistance artery, isoprostanes, nitric oxide, acetylcholine, probucol, simvastatin.
Insulin-dependent diabetes mellitus (IDDM) is associated with an increased risk of hypertension, atherosclerosis and disorders of the microcirculation and

Received: 4 August 1997 and in revised form: 29 September 1997

Corresponding author: Dr. R. M. Tribe, Department of Obstetrics and Gynaecology, St Thomas' Hospital, Lambeth Palace Road, London SE1 7EH, UK

Abbreviations: ACh, Acetylcholine; NA, noradrenaline; SNP, sodium nitroprusside; NO, nitric oxide; PSS, physiological salt solution; NEFA, non-esterified fatty acids; $\mathrm{PGF}_{2} \alpha$, prostaglandin $\mathrm{F}_{2} \alpha$; STZ, streptozotocin; HMG-CoA, 3-hydroxy 3-methylglutaryl coenzyme-A. there is increasing evidence to suggest that vascular endothelial dysfunction may play a major role. Impaired endothelium-dependent vasodilatation to acetylcholine (ACh) has been reported in aorta [1], small mesenteric [2] and femoral [3] arteries of the streptozotocin (STZ)-rat, and in diabetic patients [4, 5], and is generally associated with reduced availability of nitric oxide (NO). The factors responsible for altered NO synthesis or release are unknown and, although hyperglycaemia undoubtedly contributes [6], there is increasing evidence that oxidative stress coupled with dyslipidaemia $[7,8]$ could also be important determinants of endothelial dysfunction. Free radicals (which may be generated as a consequence of glucose-induced activation of cyclooxygenase, au- 
tooxidation of glucose or from alterations in transition metal metabolism) may cause structural alteration of DNA and modification of proteins within the endothelial cell [8]. Further damage may arise from free radical induced generation of lipid peroxides, particularly oxidised LDL, which has also been implicated directly in reduced endothelial NO synthesis [9].

Evidence for enhanced oxidative stress in diabetes includes increased concentrations of plasma lipid peroxides, oxidative modification of lipoproteins [10], altered concentrations of endogenous antioxidants [7] and, more recently, from measurements of a stable metabolite of lipid peroxidation, 8-epi-prostaglandin (PG) $\mathrm{F}_{2} \alpha$ [11]. Plasma concentrations of this isoprostane are raised in non-insulin-dependent diabetic (NIDDM) patients [12] and STZ-diabetic rats, and as we have reported recently, are decreased in diabetic rats by antioxidant supplementation [13].

A pivotal role for dyslipidaemia in diabetic endothelial dysfunction has been suggested by a study in STZ-diabetic mice in which administration of the total and LDL-cholesterol lowering drugs taurine [14] and cholestyramine [15] improved endothelium-dependent relaxation in conduit vessels. Other investigations have focused on the potential benefits of the antioxidant and antiatherogenic drug, probucol, and of the 3-hydroxy 3-methylglutaryl (HMG) coenzyme-A reductase inhibitor, simvastatin, in improving either the lipid profile of STZ-diabetic rats [1618] or vascular dysfunction of hypercholesterolaemic animals $[19,20]$ and man [21, 22]. Although the many reports of vascular dysfunction in small arteries of diabetic animals and man suggest that reduced endothelium-dependent relaxation may play an important role in the microangiopathies, there has been no study to determine the effect of either probucol or simvastatin on small artery endothelial dysfunction in diabetes.

The aim of this study therefore, was to investigate the effect of probucol and simvastatin dietary supplementation on small mesenteric artery function of the STZ-diabetic rat. In order to evaluate the role of oxidative stress and dyslipidaemia, plasma lipid analyses were performed, and lipid peroxidation assessed by measurement of 8 -epi-PGF 2 .

\section{Materials and methods}

Induction of experimental diabetes. Diabetes was induced in male Sprague-Dawley rats (250-300 g; Bantin and Kingman, Universal Ltd, Aldbrough, Hull, UK) by caudal intravenous injection of STZ $(45 \mathrm{mg} / \mathrm{kg})$ dissolved in citrate buffer $(0.1 \mathrm{~mol} / 1$ trisodium citrate, $0.1 \mathrm{~mol} / 1 \mathrm{citric}$ acid $)$. Control animals were injected with the vehicle alone. Development of diabetes was confirmed by the presence of glycosuria 3 days after injection. Animals were housed individually and provided with food and water ad libitum.
Dietary protocol. Three days after injection of either STZ or vehicle, rats were divided into the following groups: 1$)$. Diabetic rats $(n=8), 0.01 \%(\mathrm{w} / \mathrm{w})$ simvastatin in standard diet; 2$)$. Diabetic rats $(n=13), 1 \%(\mathrm{w} / \mathrm{w})$ probucol in standard diet; 3$)$. Diabetic rats $(n=10)$, standard diet; 4$)$. Control rats $(n=11)$, standard diet.

Each diet was administered for 4 weeks. An additional group of control rats was fed the probucol-supplemented diet (control rats, $n=11 ; 1 \%$ probucol (w/w) in standard diet) as, in a previous study of dietary antioxidant supplementation with vitamin $\mathrm{E}$ and vitamin $\mathrm{C}$, we demonstrated adverse effects on endothelial function in control rats [23]. In preparation of the diets, standard chow ("rat maintenance diet"; Special Diet Services, Witham, Essex, UK) was ground to a powder and mixed with either simvastatin (ground from tablet form) or probucol powder. The weight of food consumed and animal weight were recorded every 2 days throughout the experimental period.

Plasma and tissue collection. In the fifth week after injection, animals were killed by inhalation of $\mathrm{CO}_{2}$ and cervical dislocation. Samples of liver and sections of the thoracic aorta were removed from control standard-fed rats $(n=11)$, control probucol-fed rats $(n=11)$, diabetic standard-fed rats $(n=10)$ and diabetic probucol-fed rats $(n=13)$ and were immediately snap frozen in liquid nitrogen and stored at $-70^{\circ} \mathrm{C}$. Blood samples were also obtained from rats in all groups by cardiac puncture and the plasma (for measurement of glucose concentration) stored at $-70^{\circ} \mathrm{C}$. Additional blood samples were collected into ethylenediamine-tetra-acetic acid (EDTA; $28 \mathrm{mmol} / \mathrm{l}$ ) for the subsequent measurement of lipids and probucol, or into $3.8 \%$ sodium citrate (blood/anticoagulant ratio 9:1) with $14 \mu \mathrm{mol} / 1$ indomethacin (in $5 \%$ sodium bicarbonate) for assessment of 8-epi-PGF 2 . Plasma for lipid and probucol analysis was stored in EDTA $\left(50 \mathrm{mmol} / 1,-70^{\circ} \mathrm{C}\right)$ while blood samples for 8-epi-PGF $2 \alpha$ analysis were centrifuged after standing at $4{ }^{\circ} \mathrm{C}$ for $45 \mathrm{~min}\left(2400 \mathrm{~g}, 15 \mathrm{~min}, 4^{\circ} \mathrm{C}\right)$ and aliquots of the plasma supernatant stored in butylated hydroxytoluene $\left([\mathrm{BHT}] 20 \mu \mathrm{mol} / \mathrm{l}\right.$ in ethanol, $\left.-70^{\circ} \mathrm{C}\right)$ until analysis [11].

Plasma glucose and lipid analysis. Plasma glucose was measured with an enzymatic ultra violet test, using an HK/G6PDH method (Cobas Fara Centrifugal analyser, Roche Diagnostic Systems, Welwyn Garden City, UK). Plasma cholesterol and triglyceride concentrations were determined using an enzymatic colorimetric test with the in vitro diagnostic reagent systems Unimate CHOL' (using cholesterol oxidase) and Unimate TRIG' (using glycerol phosphate dehydrogenase) (Cobas Fara). Plasma high-density lipoprotein (HDL)-cholesterol was determined enzymatically using the RANDOX method based on enzymatic addition of cholesterol esterase and cholesterol oxidase after buffering of LDL, VLDL and chylomicrons (Cobas Fara). Non-esterified fatty acids (NEFA) were quantified using a Wako NEFA C test kit (Alpha laboratories, London, UK) based on an acyl-coA synthetase/acyl coA oxidase enzymatic colorimetric method. LDL-cholesterol is present at very low concentrations in these rats [24] and measurements were not performed.

Probucol and 8-epi-PGF $\mathrm{F}_{2} \alpha$ analysis in plasma and tissue. Individual aortae provided insufficient tissue for analysis. Therefore, aortae within each group were pooled and homogenised, then subdivided to provide three separate samples for extraction and subsequent evaluation of probucol and 8-epi-PGF $2 \alpha$. Liver samples were analysed individually. Tissue samples were homogenised in ice-cold chloroform/methanol solution $(2 / 2 \mathrm{v} / \mathrm{v}$ with BHT, $0.005 \%)$. Sodium chloride $(0.9 \%)$ was add- 
ed and the lipid fraction isolated by chloroform extraction. After solvent evaporation, this fraction was subjected to hydrolysis $\left(30 \mathrm{~min}, 40^{\circ} \mathrm{C}\right.$ with potassium hydroxide, $\left.1.0 \mathrm{~mol} / \mathrm{l}\right)$ and the sample divided for probucol and 8-epi-PGF $2 \alpha$ analysis. Probucol was measured by high-performance liquid chromatography according to the method of Nourooz-Zadeh et al. [25]. Quantitative analysis of total 8-epi-PGF ${ }_{2 \alpha}$ was performed by gas chromatography-mass spectrometry (GC-MS) using negative-ion chemical ionisation [11].

Assessment of vascular function. The small intestine and intact mesentery were removed from the animal and placed in cold physiological salt solution (PSS) ([mmol/l]: $119 \mathrm{NaCl} ; 25 \mathrm{NaH}-$ $\mathrm{CO}_{3} ; 5.5$ D-glucose; $1.18 \mathrm{KH}_{2} \mathrm{PO}_{4} ; 1.17 \mathrm{MgSO}_{4} ; 4.7 \mathrm{KCl} ; 2.5$ $\mathrm{CaCl}_{2} ; 0.026$ EDTA, disodium salt). Third-order branches of the mesenteric arterial arcade were dissected free of connective tissue and mounted in pairs as ring preparations on a small vessel myograph capable of measuring isometric tension. The methods have been described in detail previously [2, 26]. Briefly, arteries were bathed in PSS, gassed with $5 \% \mathrm{CO}_{2} / 95 \% \mathrm{O}_{2}$ at $37^{\circ} \mathrm{C}(\mathrm{pH} 7.45)$, and the passive tension and internal circumference determined. The arteries were then set to an internal circumference equivalent to $90 \%$ of that which would be experienced when relaxed in situ under a transmural pressure of $100 \mathrm{mmHg}$ (the maximum active tension for the minimum resting tension is developed at approximately this circumference). Arteries were then subjected to a routine 'run-up' procedure in which a total of five contractions to noradrenaline (NA, $5 \mu \mathrm{mol} / \mathrm{l}$ ), $125 \mathrm{mmol} / \mathrm{l}$ potassium solution (KPSS; PSS with equimolar substitution of $\mathrm{KCl}$ for $\mathrm{NaCl}$ ) and $5 \mu \mathrm{mol} / \mathrm{l}$ NA in KPSS were performed. All arteries produced an active tension equivalent to $100 \mathrm{mmHg}(13.3 \mathrm{kPa})$ or more, and thereby fulfilled predetermined criteria for viability. Concentration-effect curves were constructed to NA $(0.1-10 \mu \mathrm{mol} / \mathrm{l})$, with concentration increments at 2 min intervals. Following repeated washing and recovery $(10 \mathrm{~min})$ arteries were submaximally contracted with NA to achieve approximately $80 \%$ of the maximum response. Endothelium-dependent dilator function was assessed by addition of half log molar increments of $\mathrm{ACh}$ at $2 \mathrm{~min}$ intervals $\left(10^{-9}-10^{-5} \mathrm{~mol} / \mathrm{l}\right)$. A similar protocol was followed to assess endothelium-independent vasodilatation, by determining relaxation to sodium nitroprusside (SNP $\left.10^{-9}-10^{-5} \mathrm{~mol} / \mathrm{l}\right)$. All procedures were approved by the British Home Office (Project License: PPL 90/00764) and followed the "Principles of laboratory animal care" (NIH publication No.85-23, revised 1985).

Chemicals and drugs. Chemicals used in this study were: NA (Sanofi Winthrop Limited, Guildford, UK); ACh, SNP, citric acid, trisodium citrate, BHT, indomethacin, pentafluorobenzyl bromide and disisopropylethylamine (Sigma-Aldrich Co. Ltd., Poole, UK); STZ (gift from Dr. N. MacLeod, UpJohn Co. Kalamazoo, Mich., USA); $\mathrm{PGF}_{2} \alpha-\mathrm{d}_{4}$ from Cayman Chemicals (Ann Arbor, MI, USA); Sep-Pak C-18 and aminopropyl $\left(\mathrm{NH}_{2}\right)$ cartridges from Waters Chromatography (Watford, Herts, UK); N, O-bis(trimethylsily) trifluoroacetamide from Pierce Chemical Company (Rockford, Ill., USA); simvastatin as 'Zocor' tablets (Merck Sharp \& Dohme Ltd., Hoddersdon, Herts, UK) and probucol $\left(\mathrm{C}_{31} \mathrm{H}_{48} \mathrm{O}_{2} \mathrm{~S}_{2}\right)$ (Sigma-Aldrich Co. Ltd). All other chemicals were obtained from Merck Lt (Poole, UK) and all were of analytical grade. For the vascular protocols, all concentrations are expressed as final molar concentrations in the vessel chamber.

Data calculation and statistical analysis. All values are given as mean \pm SEM. For vascular protocols tension is given as the active wall tension ( $\mathrm{mN} / \mathrm{mm}$ artery length) and the relaxation re- sponses to ACh and SNP were calculated as a percentage of initial preconstriction to NA. The negative log of the concentration of agonist required to produce $50 \%$ of the maximum response $\left(\mathrm{pEC}_{50}\right)$ to $\mathrm{NA}, \mathrm{ACh}$ and $\mathrm{SNP}$ was calculated for each artery. Two arteries were used from each animal and mean values calculated. $n$ refers to the number of animals used unless otherwise stated. $\mathrm{pEC}_{50}$ was calculated for each experiment using non-linear regression, and the sigmoid equation of a curve fitting program (GraphPad; Software, San Diego, Calif., USA). Comparisons were made between mean $\mathrm{pEC}_{50}$ values and maximum relaxation of all groups (InStat GraphPad) by ANOVA, using the Tukey multiple comparison post test. Probucol plasma and tissue concentrations in control and diabetic groups were compared using the unpaired Student's $t$-test and isoprostane measurements in all groups were compared by ANOVA using the Tukey multiple comparison post test (InStat GraphPad). $n$ refers to the number of plasma or tissue samples measured (one from each animal unless otherwise stated), or to the number of extractions analysed from pooled samples in the case of aorta. Significance was assumed when $p$ was less than 0.05 .

\section{Results}

Animal weight and consumption of diet. Of the groups fed the standard diet, the diabetic animals gained less weight than controls (mean weight; diabetic standard-fed $276 \pm 11, n=9$ vs control standard-fed $375 \pm 11 \mathrm{~g}, n=11 ; p<0.001)$. There was no statistical difference between weights of probucolfed (291 $\pm 11 \mathrm{~g}, n=12)$, simvastatin-fed $(266 \pm 10 \mathrm{~g}$, $n=8$ ), or standard-fed diabetic rats. Similarly, no difference was observed between weights of control rats fed probucol $(386 \pm 9 \mathrm{~g}, n=11)$ when compared to those fed a standard diet. Diabetic rats consumed more diet per day than controls when fed the standard diet (diabetic standard-fed $50.9 \pm 3.9$ vs control standard-fed $31.3 \pm 0.8 \mathrm{~g} ; p<0.001$ ), probucol diet (diabetic probucol-fed $59.9 \pm 3.7$ vs control probucol-fed $33.2 \pm 0.8 \mathrm{~g} ; p<0.001$ ) or the simvastatin diet (diabetic simvastatin-fed $57.6 \pm 5.6 \mathrm{~g}$ vs control; $p<0.001)$. There was no difference in daily consumption among the diabetic rats fed probucol, simvastatin, or standard chow.

Plasma glucose. Plasma glucose concentration was significantly greater in diabetic standard-fed rats compared with control standard-fed rats (diabetic $38.4 \pm 2.0, n=10$ vs control $10.3 \pm 0.7 \mathrm{mmol} / \mathrm{l}, n=11$; $p<0.001)$. These values for plasma glucose concentrations of control rats are consistent with those reported in other studies from this laboratory of rats also killed by $\mathrm{CO}_{2}$ inhalation and cervical dislocation $[2,3]$. There was also a significant difference in plasma glucose concentration between diabetic probucol-fed and control probucol-fed rats (diabetic probucol-fed $40.1 \pm 1.4, n=13$ vs control probucol-fed $11.0 \pm 0.4 \mathrm{mmol} / 1, n=11 ; p<0.001)$. There was no significant difference in plasma glucose concentration of diabetic rats on standard diet, probucol-sup- 


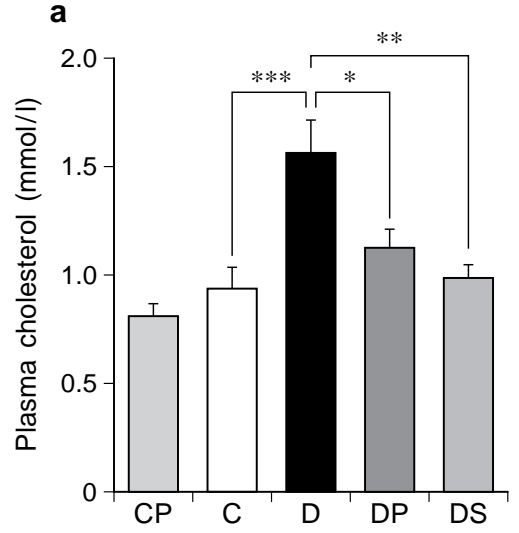

b

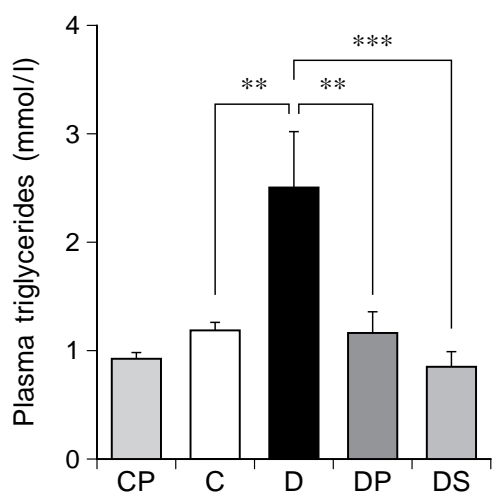

Fig. 1a-d. Plasma (a) cholesterol, (b) triglyceride, (c) HDLcholesterol, and (d) non-esterified fatty acid (NEFA) concentration $(\mathrm{mmol} / \mathrm{l})$ in control probucol-fed rats; $n=6(\mathrm{CP})$, control standard-fed rats; $n=6(\mathrm{C})$, diabetic standard-fed rats; $n=4$ (D), diabetic probucol-fed rats; $n=8$ (DP), and diabetic simvastatin-fed rats; $n=8$ (DS) on dietary supplementation for 4 weeks. $* p<0.05, * * p<0.01, * * * p<0.001$

plemented diet, or simvastatin-supplemented diet (diabetic simvastatin-fed $37.1 \pm 2.0 \mathrm{mmol} / 1, n=8$ ).

Results of lipid analysis. Plasma concentrations of cholesterol (diabetic $1.57 \pm 0.15$ vs control $0.94 \pm 0.10 \mathrm{mmol} / 1 ; p<0.001$ ) (Fig. 1 a), triglycerides (diabetic $2.51 \pm 0.51$ vs control $1.20 \pm 0.08 \mathrm{mmol} / \mathrm{l}$; $p<0.01$ ) (Fig. 1 b) and NEFA (diabetic $0.48 \pm 0.13$ vs control $0.17 \pm 0.07 \mathrm{mmol} / \mathrm{l} ; p<0.05$ ) (Fig. $1 \mathrm{~d}$ ) were significantly increased in standard-fed diabetic rats $(n=5)$ when compared to standard-fed control rats $(n=6)$. Plasma cholesterol concentration was significantly decreased in probucol-fed diabetic rats (diabetic probucol-fed $1.13 \pm 0.08 \mathrm{mmol} / \mathrm{l}, n=7$ vs diabetic standard-fed; $p<0.05)$ and in simvastatin-fed diabetic rats (diabetic simvastatin-fed $0.99 \pm$ $0.06 \mathrm{mmol} / \mathrm{l}, n=8$ vs diabetic standard-fed; $p<0.01$ ) when compared with standard-fed diabetic rats. Plasma triglyceride concentrations were similarly reduced by both probucol (diabetic probucol-fed $1.18 \pm 0.19 \mathrm{mmol} / \mathrm{l}$ vs diabetic standard-fed rats; $p<0.01$ ) and simvastatin (diabetic simvastatin-fed
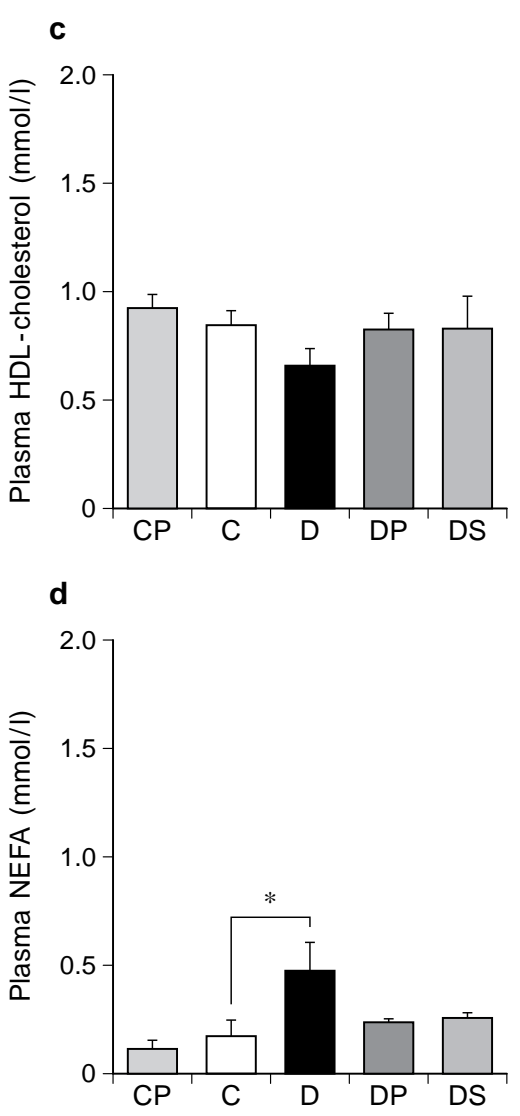

$0.86 \pm 0.14 \mathrm{mmol} / \mathrm{l}$ vs diabetic standard-fed rats; $p<0.001)$. Although numerically lower, plasma NEFA concentration in the diabetic rats was not significantly decreased by probucol (diabetic probucolfed $0.23 \pm 0.02 \mathrm{mmol} / \mathrm{l}$ ) or by simvastatin (diabetic simvastatin-fed $0.26 \pm 0.02 \mathrm{mmol} / \mathrm{l}$ ) when compared to standard-fed diabetic. Probucol-fed control rats $(n=6)$ showed no difference in plasma cholesterol $(0.81 \pm 0.06 \mathrm{mmol} / \mathrm{l})$, triglyceride $(0.94 \pm 0.06 \mathrm{mmol} /$ 1), NEFA $(0.12 \pm 0.07 \mathrm{mmol} / \mathrm{l})$ or HDL-cholesterol $(0.92 \pm 0.07 \mathrm{mmol} / \mathrm{l})$ concentrations compared to standard-fed controls. Plasma HDL-cholesterol (Fig. 1c) concentration was not different in standardfed diabetic $(0.66 \pm 0.07 \mathrm{mmol} / \mathrm{l})$ and standard-fed control $(0.84 \pm 0.07 \mathrm{mmol} / \mathrm{l})$ rats, nor was it different in probucol-fed diabetic $(0.82 \pm 0.08 \mathrm{mmol} / \mathrm{l})$ or simvastatin-fed diabetic $(0.83 \pm 0.15 \mathrm{mmol} / \mathrm{l})$ compared to standard-fed diabetic rats.

Tissue and plasma probucol content. Probucol was assayed and detected in the lipid fractions of plasma, liver and aortic tissue from both diabetic and control rats on the probucol-supplemented diet and was not measurable in control or diabetic animals fed the standard diet. There was a $95 \%$ increase in plasma probucol concentration in diabetic compared with control probucol-fed rats (diabetic probucol-fed $11.27 \pm 1.07, n=7 \quad$ vs control probucol-fed $5.79 \pm$ $0.67 \mu \mathrm{mol} / 1, n=6 ; p<0.005)$ (Fig. $2 \mathrm{a}$ ). Probucol content of the aorta ( $n=3$ pooled sample) was increased 


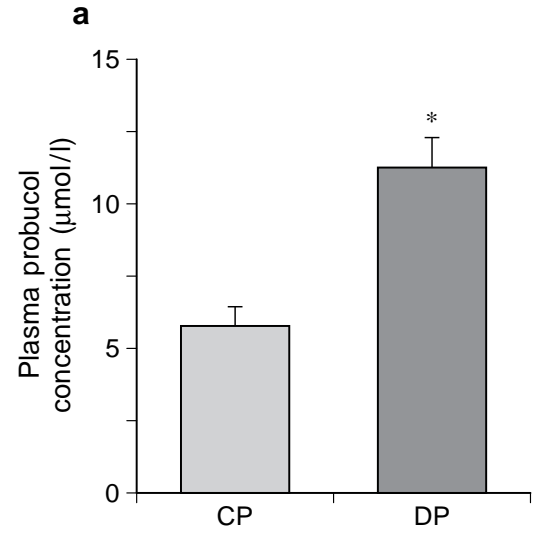

b

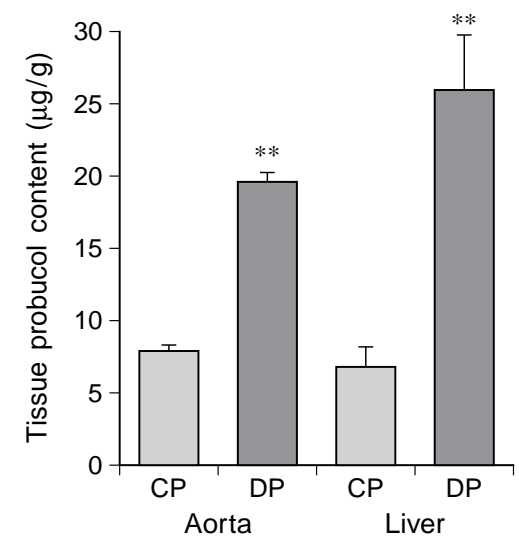

Fig. 2a-b. Plasma (a) probucol concentration ( $\mu \mathrm{mol} / \mathrm{l})$, and liver and aortic (b) probucol content $(\mu \mathrm{g} / \mathrm{g})$ of control probucol-fed (CP) and diabetic probucol-fed (DP) rats (1\% probucol-supplemented diet for 4 weeks). ${ }^{*} p<0.005, * * p<0.0005$

by $140 \%$ (diabetic probucol-fed $19.48 \pm 0.78$ vs control probucol-fed $8.13 \pm 0.26 \mu \mathrm{g} / \mathrm{g} ; \quad p<0.0005)$ (Fig. 2 b) and liver probucol content was increased by $277 \%$ (diabetic probucol-fed $25.84 \pm 3.82, n=13$ vs control probucol-fed $6.86 \pm 1.38 \mu \mathrm{g} / \mathrm{g}, \quad n=11$; $p<0.0005$ Mann Whitney) (Fig. 2b) in probucol-fed diabetic when compared to probucol-fed control rats.

Plasma concentrations of 8-epi-PGF $F_{2 \alpha}$. Plasma 8-epi$\mathrm{PGF}_{2 \alpha}$ concentration was measured in standard-fed and probucol-fed control and diabetic rats. Plasma concentrations of 8-epi-PGF ${ }_{2 \alpha}$ (Fig. 3 a) were numerically higher in standard-fed diabetic $(7.26 \pm 2.47$ $\mathrm{nmol} / \mathrm{l}, n=4)$ when compared to standard-fed control rats $(0.99 \pm 0.78 \mathrm{nmol} / \mathrm{l}, n=6)$ but this difference did not achieve statistical significance and probucol-supplementation did not significantly reduce the plasma concentration of 8-epi-PGF $2 \alpha$ in the probucol-fed diabetic rats $(5.75 \pm 1.09 \mathrm{nmol} / \mathrm{l}, n=6)$. 8 -epi-PGF ${ }_{2 \alpha}$ was significantly raised in plasma of probucol-fed control rats when compared to control (control probucol-fed $12.43 \pm 46 \mathrm{nmol} / \mathrm{l}, n=6$ vs control standard-fed; $p<0.01)$.

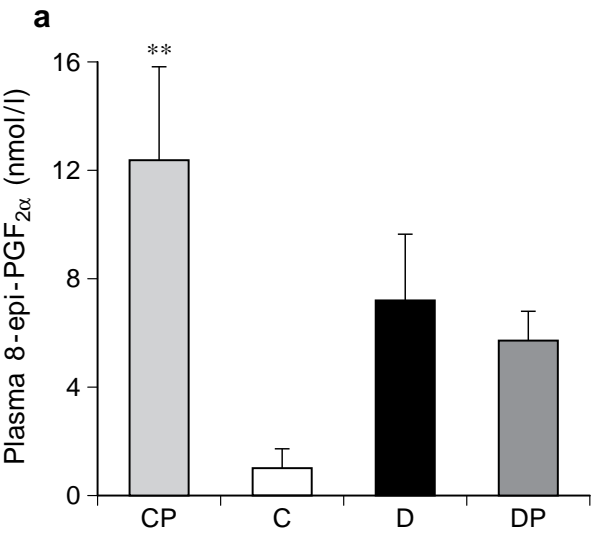

b

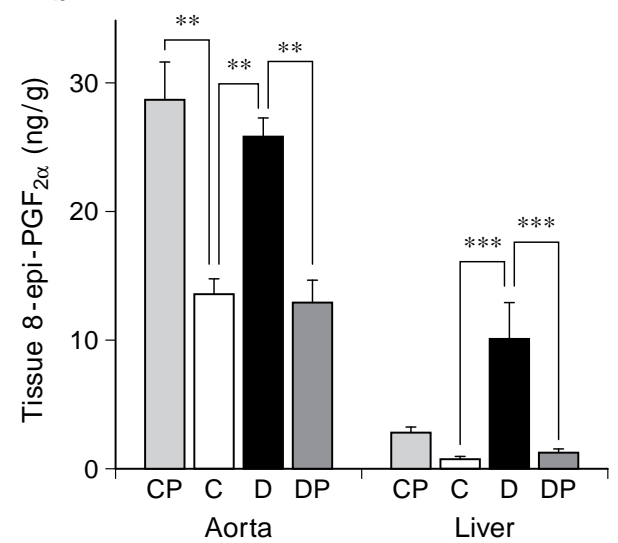

Fig. 3a-b. Plasma (a) 8-epi-PGF ${ }_{2 \alpha}$ concentration (nmol/l), and liver and aortic (b) 8-epi-PGF $2 \alpha$ content (ng/g) of control probucol-fed rats (CP), control standard-fed rats; $n=6(\mathrm{C})$, diabetic standard-fed rats; $n=4$ (D) and diabetic probucol-fed rats (DP) on $1 \%$ probucol-supplemented diet for 4 weeks. $* * p<0.01, * * * p<0.001$

Tissue content of 8-epi-PGF $F_{2 \alpha}$. The 8-epi-PGF ${ }_{2 \alpha}$ content of both aorta and liver (Fig. $3 \mathrm{~b}$ ) was measured in standard-fed and probucol-fed control and diabetic rats. 8-epi-PGF ${ }_{2 \alpha}$ was significantly increased in aorta of diabetic standard-fed rats when compared with controls (diabetic standard-fed $25.76 \pm 1.47$ vs control standard-fed $13.57 \pm 1.28 \mathrm{ng} / \mathrm{g} ; p<0.01)$. Dietary probucol supplementation in diabetic rats reduced aortic 8-epi-PGF ${ }_{2 \alpha}$ content to values similar to those of control standard-fed rats (diabetic probucol-fed $13.00 \pm 1.64 \mathrm{ng} / \mathrm{g}$ vs diabetic standard-fed; $p<0.01$ ). Conversely, probucol supplementation in control rats increased the aortic content of 8 -epi-PGF $\mathrm{PG}_{2 \alpha}$ to values higher than those observed in the diabetic rats (control probucol-fed $28.64 \pm 2.89 \mathrm{ng} / \mathrm{g}$ vs control standard-fed; $p<0.01$ ).

Liver content of 8-epi-PGF ${ }_{2 \alpha}$ was significantly increased in diabetic rats when compared to control standard-fed rats (diabetic standard-fed $10.20 \pm 2.77$, $n=10$ vs control standard-fed $0.96 \pm 0.16 \mathrm{ng} / \mathrm{g}, n=7$; $p<0.001)$. Probucol supplementation in diabetic rats $(n=13)$ significantly reduced liver 8 -epi- $\mathrm{PGF}_{2 \alpha}$ con- 


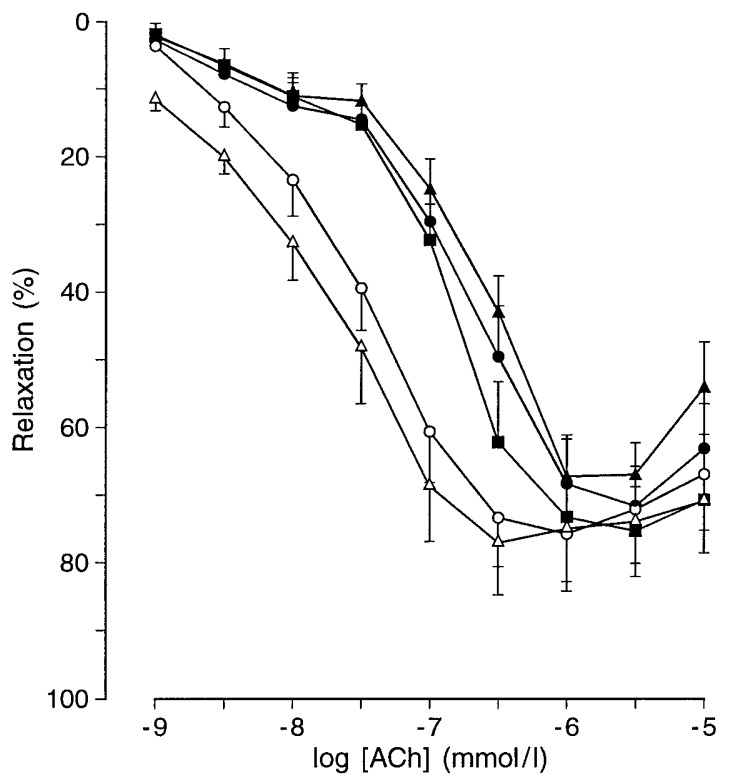

Fig. 4. Relaxation of small mesenteric arteries in response to increased concentrations of acetylcholine (ACh) in control standard-fed rats; $n=8(\bigcirc)$, control probucol-fed rats; $n=9$ $(\nabla)$, diabetic standard-fed rats; $n=8(\bigcirc)$, diabetic probucolfed rats; $n=8(\boldsymbol{\nabla})$ or diabetic simvastatin-fed rats; $n=8(\square)$ on dietary supplementation for 4 weeks

tent towards control standard-fed values (diabetic probucol-fed $1.52 \pm 0.18 \mathrm{ng} / \mathrm{g}$ vs diabetic standardfed; $p<0.001)$. There was no significant difference in liver 8-epi-PGF ${ }_{2 \alpha}$ content between probucol-fed and standard-fed control rats (control probucol-fed $2.95 \pm 0.55 \mathrm{ng} / \mathrm{g}, n=11$ vs control standard-fed).

Vascular function. Mean mesenteric arterial internal diameter was $300 \pm 5 \mu \mathrm{m}(n=80$ arteries $)$ and there was no statistical difference in artery diameter between groups. Preconstricted arteries from both control $(n=8)$ and diabetic $(n=8)$ rats relaxed in a concentration dependent manner to ACh. As reported previously [2], mesenteric arteries from diabetic animals on the standard diet demonstrated a significant reduction in sensitivity $\left(\mathrm{pEC}_{50}\right)$ to $\mathrm{ACh}$ when compared to controls (Table 1, Fig.4). Relaxation to ACh was not different in probucol-fed diabetic rats when compared to standard-fed diabetic rats. ACh-induced relaxation of arteries from probucol-fed control rats was also not different to those of standard-fed control rats. Mesenteric arteries from probucol-fed control and diabetic rats showed similar responses to NA or SNP to those of standard-fed control and diabetic rats (Table 1, Fig.4). Similarly, arteries from diabetic rats on simvastatin supplementation $(n=8)$ demonstrated a significant reduction in sensitivity to ACh compared with control rats on standard diet and there was no difference between $\mathrm{pEC}_{50}$ or maximum response of arteries from diabetic rats on simvastatin or standard chow (Table 1, Fig.4). Responses to SNP were not altered by simvastatin supplementation.

\section{Discussion}

This study has investigated the relationship of oxidative stress and abnormal plasma lipid concentration to vascular dysfunction of small mesenteric arteries in the STZ-rat. Determination of the function of these small arteries provides important insight into the mechanisms contributing to abnormal resistance in small arteries and arterioles and hence to disturbed capillary blood flow, both of which are associated with the vasculopathies of diabetes [27]. Several previous studies have documented a defect in ACh-mediated endothelium-dependent relaxation in the STZ-rat and this agonist was also used in the present study, as a blunted ACh-induced relaxation seems to be indicative of a global defect in the endothelium $[6,28]$.

The abnormal lipid profile of the STZ-diabetic rats in this study was similar to that previously reported $[16,18,24,29]$. Other studies have shown elevation [18] and oxidation [10] of LDL in STZ-diabetic rats

Table 1. Effects of probucol and simvastatin dietary supplementation on vascular responses to ACh, NA and SNP of small mesenteric arteries from STZ-diabetic and control rats

\begin{tabular}{|c|c|c|c|c|c|c|}
\hline & & $\begin{array}{l}\text { Control } \\
\text { standard-fed } \\
(n=8)\end{array}$ & $\begin{array}{l}\text { Control } \\
\text { probucol-fed } \\
(n=9)\end{array}$ & $\begin{array}{l}\text { Diabetic } \\
\text { standard-fed } \\
(n=8)\end{array}$ & $\begin{array}{l}\text { Diabetic } \\
\text { probucol-fed } \\
(n=8)\end{array}$ & $\begin{array}{l}\text { Diabetic } \\
\text { simvastatin-fed } \\
(n=8)\end{array}$ \\
\hline $\mathbf{N A}$ & $\mathrm{pEC}_{50}$ & $\mathbf{5 . 8 9 1} \pm 0.061$ & $\mathbf{5 . 7 4 2} \pm 0.040$ & $\mathbf{5 . 8 1 7} \pm 0.031$ & $\mathbf{5 . 8 4 2} \pm 0.045$ & $\mathbf{5 . 7 0 4}^{\mathbf{a}} \pm 0.045$ \\
\hline \multirow[t]{2}{*}{$\mathbf{A C h}$} & $\mathrm{pEC}_{50}$ & $\mathbf{7 . 5 4 1} \pm 0.175$ & $\mathbf{7 . 4 6 6} \pm 0.180$ & $\mathbf{6 . 7 6 3}^{\mathbf{a}} \pm 0.172$ & $\mathbf{6 . 6 9 3}^{\mathbf{b}} \pm 0.112$ & $\mathbf{6 . 7 5 4}^{\mathbf{a}} \pm 0.078$ \\
\hline & Max & $\mathbf{1 7 . 0} \pm 6.4$ & $\mathbf{2 4 . 0} \pm 10.1$ & $\mathbf{2 0 . 9} \pm 6.3$ & $\mathbf{2 7 . 7} \pm 6.3$ & $\mathbf{1 6 . 0} \pm 6.5$ \\
\hline SNP & Max & $\mathbf{1 9 . 6} \pm 9.8$ & $\mathbf{1 7 . 3} \pm 4.4$ & $\mathbf{3 5 . 0} \pm 8.0$ & $\mathbf{3 0 . 3} \pm 3.8$ & $\mathbf{3 5 . 5} \pm 11.0$ \\
\hline
\end{tabular}

${ }^{\mathbf{a}} p<0.05$ Tukey compared to control standard-fed; ${ }^{\mathbf{b}} p<0.05$ Tukey compared to control probucol-fed. Max refers to maximum tension $(\mathrm{mN} / \mathrm{mm})$ achieved to noradrenaline or maximum \% relaxation to ACh or SNP. All values are expressed as mean \pm SEM 
and this reactive lipid has been proposed to contribute to endothelial damage, while excess fatty acids $[30,31]$ and elevated triglycerides [32] may also affect endothelial function. Despite the potential for lipidinduced endothelial damage, this study clearly demonstrated that dietary supplementation with the HMG Co-A reductase inhibitor simvastatin $(0.01 \%)$ reversed the hypercholesterolaemia and hypertriglyceridaemia of the diabetic rats but did not affect vascular endothelial function of small mesenteric arteries. Similarly, dietary supplementation with the antioxidant lipid-lowering agent probucol $(1 \%)$ significantly improved both oxidative stress and dyslipidaemia of the diabetic rats but failed to improve vascular function.

This is, to our knowledge, the first investigation of the effect of lipid-lowering therapy on resistancesized arteries from diabetic animals, although beneficial actions of the lipid lowering drugs, taurine [14] and cholestyramine [15], have been reported in aortae of diabetic mice. These opposing results may reflect variance in the initial lipid profile between diabetic mouse and rat. Alternatively, differences in the relative contributions of NO, prostaglandins and endothelium-derived hyperpolarizing factor to endothelium-dependent dilatation in rat resistance and mouse conduit arteries may be responsible.

In this study, there was no abnormality of the noradrenaline response in the diabetic compared with the control rats which differs from a previous study from our laboratory in female Wistar rats [2] and may suggest some strain and gender difference in catecholamine responsiveness in diabetic rats.

While studies investigating the relationship between dyslipidaemia and vascular endothelial function in diabetes are relatively few, the response to lipid lowering therapy in other disease states has been more widely reported and generally shows improvement of vascular function in hypercholesterolaemic animals $[19,20,33]$ and human subjects with atherosclerosis [21, 34-36]. However, two studies have reported that probucol did not improve forearm vascular responses to ACh [37] or delay the progression of femoral atherosclerosis [38] in hypercholesterolaemic patients, despite increasing the resistance of LDL to oxidation and reducing plasma LDL-cholesterol concentration. The lack of correction of the endothelial defect in the present study compared with that in non-diabetic hypercholesterolaemic animals, suggests that metabolic disturbances other than hypercholesterolaemia are more detrimental to vascular endothelial function in this animal model of diabetes.

As probucol has antioxidant as well as lipid lowering properties, probucol accumulation into, and antioxidant efficacy in, the lipid fraction of plasma and the vasculature was determined. Probucol was present in plasma, liver and aorta of probucol-fed animals and consistently higher levels were observed in the diabetic rats compared to control. The 1.8 -fold increase in the daily food consumption of the diabetic rats is unlikely to explain the 2.4 and 3.8-fold rise in probucol content of aorta and liver respectively. These data therefore suggest that tissue uptake of probucol may be enhanced in the STZ-diabetic rat.

The high plasma concentrations and raised aortic and liver content of 8-epi-PGF ${ }_{2 \alpha}$ confirmed our earlier observations of oxidative stress in the diabetic rats [23] and the reversal by probucol suggested that the drug is indeed an effective antioxidant. To our knowledge, no previous study has reported direct evidence for oxidative stress in the vasculature of diabetic animals. $\mathrm{F}_{2}$-isoprostanes are initially formed by oxidative modification of arachidonic acid in phospholipid membranes $[39,40]$. The observation that probucolsupplemented control rats exhibited greatly increased plasma concentration and aortic 8-epi$\mathrm{PGF}_{2 \alpha}$ content was unexpected. One explanation might be that probucol has a direct effect on arachidonic acid metabolism, but if this were the case a similar increase in 8-epi-PGF ${ }_{2 \alpha}$ would be anticipated in control and diabetic animals. Despite the observation that the probucol-fed control rats had greater tissue 8 -epi-PGF ${ }_{2 \alpha}$ content, vascular function was no different to that of standard-fed control rats, thus providing further evidence for a dissociation between lipid peroxidation and vascular function.

This study supports a recent investigation from this laboratory, which demonstrated that dietary supplementation of vitamins $\mathrm{E}$ and $\mathrm{C}$ failed to improve vascular function in diabetic rats despite reducing oxidative stress as measured by evaluation of 8 -epi-PGF ${ }_{2 \alpha}$ [23]. In summary, although probucol and simvastatin successfully reversed dyslipidaemia in the STZ-diabetic rat, these drugs failed to inhibit the development of endothelial dysfunction in small mesenteric arteries. Whether these observations pertain to all vascular beds in this animal model remains to be evaluated. This study provides further evidence that oxidative stress and abnormal lipids are not key mediators of impaired vascular function in small arteries of this animal model of diabetes, and point to a critical role of hyperglycaemia per se which was unaffected by any of the dietary regimes.

Acknowledgements. The authors thank the British Heart Foundation for supporting this project (grant number: PG/94186), Professor Tony Mallet for access to the UMDS Mass Spectrometry Facility for isoprostane analysis, and to Mr Peter Lumm (Department of Chemical Pathology, St Thomas' Hospital) for lipid analyses. 


\section{References}

1. Cameron NE, Cotter MA (1992) Impaired contraction and relaxation in aorta from streptozotocin-diabetic rats: role of polyol pathway. Diabetologia 35: 1011-1019

2. Taylor PD, McCarthy AL, Thomas CR, Poston L (1992) Endothelium-dependent relaxation and noradrenaline sensitivity in mesenteric arteries of streptozotocin-induced diabetic rats. Br J Pharmacol 107: 393-399

3. Taylor PD, Graves JE, Poston L (1995) Selective impairment of acetylcholine-mediated endothelium-dependent relaxation in isolated resistance arteries of the streptozotocin-induced diabetic rat. Clin Sci 88: 1-6

4. McNally PG, Watt PAC, Rimmer T et al. (1994) Impaired contraction and endothelium-dependent relaxation in isolated resistance vessels from patients with insulin-dependent diabetes mellitus. Clin Sci 87: 31-36

5. Johnstone MT, Creager SJ, Scales KM et al. (1993) Impaired endothelium-dependent vasodilation in patients with insulin-dependent diabetes mellitus. Circulation 88: 2510-2516

6. Poston L, Taylor PD (1995) Endothelium-mediated vascular function in insulin-dependent diabetes mellitus. Clin Sci 88: 245-255

7. Tribe RM, Poston L (1996) Oxidative stress and lipids in diabetes: a role in endothelium vasodilator dysfunction? Vasc Med 1: 195-206

8. Wolff SP (1993) Diabetes mellitus and free radicals. Br Med Bull 49: $642-652$

9. Liao JK, Shin WS, Lee WY, Clark SL (1995) Oxidised low-density lipoprotein decreases the expression of endothelial nitric oxide synthase. J Biol Chem 270: 319-324

10. Morel DW, Chisolm GM (1989) Antioxidant treatment of diabetic rats inhibits lipoprotein oxidation and cytotoxicity. J Lipid Res 30: 1827-1834

11. Nourooz-Zadeh J, Gopaul NK, Barrow S, Mallet AI, Anggard EE (1996) Analysis of $F_{2}$-isoprostanes as indicators of non-enzymatic lipid peroxidation in vivo by gas chromatography-mass spectrometry: development of a solid-phase extraction procedure. J Chromatogr B 667: 199-208

12. Gopaul NK, Anggard EE, Mallet AI et al. (1995) Plasma 8-epi$\mathrm{PGF}_{2} \alpha$ levels are elevated in individuals with non-insulin dependent diabetes mellitus. FEBS Lett 368: 225-229

13. Puri S, Gopaul N, Palmer AM et al. (1996) Plasma levels of 8epi-PGF $\mathrm{PG}_{2} \alpha$ in diabetic rats are reduced by vitamins $\mathrm{E}$ and $\mathrm{C}$. VIII Biennial Meeting, International Society for Free Radical Research:P02 (Abstract)

14. Kamata K, Sugiura M, Kojima S, Kasuya Y (1996) Restoration of endothelium-dependent relaxation in both hypercholesterolaemia and diabetes by chronic taurine. Eur J Pharmacol 303: 47-53

15. Kamata K, Sugiura M, Kojima S, Kasuya Y (1996) Preservation of endothelium-dependent relaxation in cholesterol-fed and streptozotocin-induced diabetic mice by the chronic administration of cholestyramine. Br J Pharmacol 118: 385-391

16. Mamo JCL, Elsegood CL, Umeda Y, Hirano T, Redgrave TG (1993) Effect of probucol on plasma clearance and organ uptake of chylomicrons and VLDLs in normal and diabetic rats. Arterioscler Thromb 13: 231-239

17. Maeda E, Yoshino G, Matsushita M et al. (1993) Effect of a 3-hydroxy-3-methylglutaryl coenzyme A reductase inhibitor on triglyceride kinetics in chronically streptozotocin-diabetic rats. Metabolism 42: 52-57

18. Yoshino G, Matsushita M, Maeda E et al. (1994) Effect of longterm administration of probucol on triglyceride turnover in rats. Coron Artery Dis 5: 67-2

19. Keaney JF, Xu A, Cunningham D et al. (1995) Dietary probucol preserves endothelial function in cholesterol-fed rabbits by limiting vascular oxidative stress and superoxide generation. J Clin Invest 95: 2520-2529

20. Simon BC, Haudenschild CC, Cohen RA (1993) Preservation of endothelium-dependent relaxation in atherosclerotic rabbit aorta by probucol. J Cardiovasc Pharmacol 21: 893-901
21. Goode GK, Heagerty AM (1995) In vitro responses of human peripheral small arteries in hypercholesterolemia and effects of therapy. Circulation 91: 2898-2903

22. Stroes ESG, Koomans HA, de Bruin TWA, Rabelink TJ (1995) Vascular function in the forearm of hypercholesterolaemic patients off and on lipid-lowering medication. Lancet 346: 467-471

23. Palmer AM, Thomas CR, Gopaul N, Dhir S, Änggård EE, Poston L, Tribe RM (1998) Dietary antioxidant supplementation reduces lipid peroxidation but impairs vasuclar function in small mesenteric arteries of the streptozotocin-diabetic rat. Diabetologia 41: 148-156

24. Ebara T, Hirano T, Mamo JCL et al. (1994) Hyperlipidemia in streptozocin-diabetic hamsters as a model for human insulin-deficient diabetes: comparison to streptozocin-diabetic rats. Metabolism 43: 299-305

25. Nourooz-Zadeh J, Gopaul NK, Forster LA, Ferns GAA, Anggard EE (1994) Measurement of plasma probucol levels by high-performance liquid chromatography. J Chromatogr B 654: 55-60

26. Mulvany MJ, Halpern W (1977) Contractile properties of small arterial resistance vessels in spontaneously hypertensive and normotensive rats. Circ Res 41: 19-26

27. Tooke JE (1986) Microvascular haemodynamics in diabetes mellitus. Clin Sci 70: 119-125

28. Tribe RM, Thomas CR, Poston L (1998) Flow-induced dilatation in isolated resistance arteries from control and streptozotocin-diabetic rats. Diabetologia 41: 34-39

29. Tada H, Oida K, Kutsumi Y et al. (1992) Effects of probucol on impaired cardiac performance and lipid metabolism in streptozotocin-induced diabetic rats. J Cardiovasc Pharmacol 20: 179186

30. Hennig B, Ramasamy S, Alvarado A et al. (1993) Selective disruption of endothelial barrier function in culture by pure fatty acids and fatty acids derived from animal and plant fats. J Nutr 123: $1208-1216$

31. Crosby AJ, Wahle KW, Duthie GG (1996) Modulation of glutathione peroxidase activity in human vascular endothelial cells by fatty acids and the cytokine interleukin-1 beta. Biochim Biophys Acta 1303: 187-192

32. Watts GF, O'Brien SF, Silvester W, Millar JA (1996) Impaired endothelium-dependent and independent dilatation of forearm resistance arteries in men with diet-treated non-insulin-dependent diabetes: role of dyslipidaemia. Clin Sci 91: 567-573

33. Plane F, Jacobs M, McManus D, Bruckdorfer KR (1993) Probucol and other antioxidants prevent the inhibition of endothelium-dependent relaxation by low density lipoproteins. Atherosclerosis 103: 73-79

34. Treasure CB, Klein JL, Weintraub WS et al. (1995) Beneficial effects of cholesterol-lowering therapy on the coronary endothelium in patients with coronary artery disease. N Engl J Med 332: 481-487

35. Anderson TJ, Meredith IT, Yeung AC et al. (1995) The effect of cholesterol-lowering and antioxidant therapy on endotheliumdependent coronary vasomotion. N Engl J Med 332: 488-493

36. O'Driscoll G, Green D, Taylor RR (1997) Simvastatin, an HMGcoenzyme A reductase inhibitor, improves endothelial function within 1 month. Circulation 95: 1126-1131

37. McDowell IFW, Brennan GM, McEneny J et al. (1994) The effect of probucol and vitamin $E$ treatment on the oxidation of low-density lipoprotein and forearm vascular responses in humans. Eur J Clin Invest 24: 759-765

38. Regnstrom J, Walldius G, Nilsson S et al. (1996) The effect of probucol on low density lipoprotein oxidation and femoral atherosclerosis. Atherosclerosis 125: 217-229

39. Kuzuya M, Kuzuya F (1993) Probucol as an antioxidant and antiatherogenic drug. Free Radic Biol Med 14: 67-77

40. Moore KP, Darley-Usmar VM, Morrow J, Roberts LJ (1995) Formation of $\mathrm{F}_{2}$-isoprostanes during oxidation of human lowdensity lipoprotein and plasma by peroxynitrite. Circ Res 77: 335-341 